Farum

Sociológico

\section{Forum Sociológico}

Série II

39 | 2021

Covid-19: Acesso a direitos, desigualdades sociais e (re)arranjos institucionais no controle da pandemia em Portugal e no Brasil

\title{
A justiça brasileira sob medida : A pandemia no Brasil entre direitos e privilégios
}

Brazilian custom-made judiciary: The pandemic in Brazil between rights and privileges

Bárbara Gomes Lupetti Baptista, Fernanda Duarte, Michel Lobo Toledo Lima, Rafael Mario Iorio Filho e Roberto Kant de Lima

\section{(2) OpenEdition}

\section{Edição electrónica}

URL: https://journals.openedition.org/sociologico/9952

DOI: 10.4000/sociologico.9952

ISSN: $2182-7427$

Editora

CICS.NOVA - Centro Interdisciplinar de Ciências Sociais da Universidade Nova de Lisboa

\section{Edição impressa}

Paginação: 19-30

ISSN: 0872-8380

Refêrencia eletrónica

Bárbara Gomes Lupetti Baptista, Fernanda Duarte, Michel Lobo Toledo Lima, Rafael Mario Iorio Filho e Roberto Kant de Lima, «A justiça brasileira sob medida : A pandemia no Brasil entre direitos e

privilégios», Forum Sociológico [Online], 39 | 2021, posto online no dia 23 novembro 2021, consultado o 29 março 2022. URL: http://journals.openedition.org/sociologico/9952 ; DOI: https://doi.org/10.4000/ sociologico.9952 


\section{A JUSTIÇA BRASILEIRA SOB MEDIDA: A PANDEMIA NO BRASIL ENTRE DIREITOS E PRIVILÉGIOS}

\section{BRAZILIAN CUSTOM-MADE JUDICIARY: THE PANDEMIC IN BRAZIL BETWEEN RIGHTS AND PRIVILEGES}

https://doi.org/10.4000/sociologico.9952

\section{Bárbara Gomes Lupetti Baptista}

- Universidade Federal Fluminense, Faculdade de Direito, Departamento de Ciências Judiciárias DCJ/UFF \& Universidade Veiga de Almeida, Programa de Pós-graduação Stricto Sensu em Direito \& Universidade Federal Fluminense, Instituto de Estudos Comparados em Administração Institucional de Conflitos - INCT-InEAC, Rio de Janeiro, Brasil. ORCID: https:// orcid.org/000-0001-8342-4543

Fernanda Duarte

- Universidade Federal Fluminense, Faculdade de Direito, Departamento de Ciências Judiciárias - DCJ/UFF \& Universidade Federal Fluminense, Programa de Pós-Graduação Justiça Administrativa - PPGJA/UFF \& Universidade Estácio de Sá, Programa de Pós-Graduação em Direito \& Universidade Federal Fluminense, Instituto de Estudos Comparados em Administração Institucional de Conflitos - INCT-InEAC, Rio de Janeiro, Brasil. ORCID: https://orcid.org/0000-00032156-6946

Michel Lobo Toledo Lima

Fundação de Amparo à Pesquisa do Estado do Rio de Janeiro - FAPERJ \& Universidade Federal Fluminense, Instituto de Estudos Comparados em Administração Institucional de Conflitos - INCT-InEAC, Rio de Janeiro, Brasil. ORCID: https:// orcid.org/0000-0001-6259-288X

Rafael Mario Iorio Filho

Universidade Federal Fluminense, Faculdade de Direito, Departamento de Ciências Judiciárias \& Fundação de Amparo à Pesquisa do Estado do Rio de Janeiro - FAPERJ \& Universidade Veiga de Almeida, Programa de Pós-Graduação em Direito \& Universidade Federal Fluminense, Instituto de Estudos Comparados em Administração Institucional de Conflitos - INCT-InEAC, Rio de Janeiro, Brasil. ORCID: https://orcid.org/0000-0003-3725-5069

\section{Roberto Kant de Lima}

Universidade Federal Fluminense, Programa de Pós-Graduação em Antropologia - PPGA/UFF \& Universidade Federal Fluminense, Programa de Pós-Graduação em Justiça e Segurança - PPGJS/UFF \& Universidade Veiga de Almeida, Programa de Pós-Graduação em Direito \& Universidade Federal Fluminense, Instituto de Estudos Comparados em Administração Institucional de Conflitos - INCT-InEAC \& Conselho Nacional de Desenvolvimento Científico e Tecnológico - CNPq \& Fundação de Amparo à Pesquisa do Estado do Rio de Janeiro - FAPERJ, Rio de Janeiro, Brasil. ORCID: https://orcid. org/0000-0003-1367-9318

\section{Resumo}

Partindo da afirmação de que a sociedade brasileira se estrutura de forma hierarquizada, reproduzindo um ethos aristocrático em contraposição a uma ordem republicana, podemos reconhecer que, no plano jurídico, a desigualdade se opera em dois níveis: no aspecto normativo - por meio da elaboração das leis - e na administração dos conflitos, quando da aplicação das leis, especialmente pelo Judiciário. Nesse texto pretendemos problematizar o modo como as instituições judiciárias no Brasil internalizam e (re)produzem desigualdades jurídicas - o que se tornou mais evidente com a pandemia da Covid-19 e suas consequências para a esfera de direitos dos brasileiros. Para tanto, pretendemos descrever três categorias de casos (os casos de auxílio-saúde; casos de "fura-fila" da vacinação contra a Covid-19; e os casos de pedidos de liberdade de réus presos em razão da pandemia da Covid-19), que ajudam a revelar essa chave da desigualdade.

Palavras-chave: igualdade jurídica brasileira, judiciário, Covid-19 


\begin{abstract}
Based on the assertion that Brazilian society is structured in a hierarchical manner, reproducing an aristocratic ethos as opposed to a republican order, we can recognize that, on the legal level, inequality operates on two levels: in the normative aspect - through the drafting of laws - and in conflict management, when the laws are applied, especially by the judiciary. In this paper we intend to problematize how judicial institutions in Brazil internalize and (re)produce legal inequalities - which became more evident with the Covid-19 pandemic and its consequences for the rights of Brazilians. To this end, we intend to describe three categories of cases (the cases of health aid; cases of "fura-fila" of the vaccination against Covid-19 and the cases of requests for freedom of defendants imprisoned due to the Covid-19 pandemic) that help reveal this key of inequality.
\end{abstract}

Keywords: Brazilian equal protection view, equality, judiciary, Covid-19

\section{Introdução: A desigualdade jurídica e a pandemia da covid-19}

Ao longo da pandemia da covid-19, houve um discurso, classificado como de senso comum, que compôs inúmeros escritos e notícias jornalísticas no começo da sua disseminação, no sentido de que a doença causada pelo referido vírus seria "democrática" ${ }^{11}$, uma vez que este não distinguia as vítimas quanto à cor, ao status ou à classe social, à escolaridade, à localidade, entre outras características. Porém, há pelo menos duas questões que pesquisadores de diversas áreas têm apontado, no sentido do tensionamento dessa afirmação: a primeira é que, embora o vírus não seja seletivo em relação a quem atingirá, suas formas de transmissão, em contraposição às de prevenção, assim como o risco de adoecimento e de morte, são potencializados em certos grupos sociais e em certas localidades (Fiocruz, 2020; G. Silva, 2021); a segunda se dá ao observar e analisar como as instituições têm registrado, percebido e administrado esses casos (Lima \& Campos, 2021; L. R. C. Oliveira, 2021; Ribeiro \& V. Oliveira, 2020).

Partindo da segunda questão, nosso objetivo é descrever e problematizar como as instituições judiciárias no Brasil internalizam e (re)produzem desigualdades. Como já apontou Roberto DaMatta (1979), se os cidadãos, nas relações sociais diárias, não se percebem como iguais, o Judiciário brasileiro acaba por reproduzir essa mesma percepção, não os considerando (e tratando) assim. Em outras palavras, a afirmação de que a sociedade brasileira se estrutura juridicamente de forma hierarquizada, reproduzindo um ethos aristocrático em contraposição a uma ordem republicana, permite reconhecer que, no plano jurídico, a desigualdade se opera em dois níveis: no aspecto normativo - por meio da elaboração das leis - e na administração dos conflitos - no momento da aplicação das leis, especialmente pelo Judiciário (Duarte, Iorio Filho \& Baptista, 2021).
O papel normalizador que os tribunais desempenham nas sociedades liberais burguesas igualitárias, no Brasil, de forma peculiar, se caracteriza pelo reforço dessa desigualdade, na contramão dos ideais republicanos acolhidos formalmente nos textos normativos ${ }^{2}$ (Amorim, Baptista, Duarte, M. L. T. Lima \& R. K. Lima, 2021; Duarte, 2006; Duarte \& Iorio Filho, 2011; M. L. T. Lima \& R. K. Lima, 2020).

Nosso problema, então, pode ser assim desenhado: se os juízes têm o dever de tratar as partes com igualdade, como estabelece a Constituição da República, como é possível se ter como resultado prático, por meio de sua atuação no processo, a aplicação da lei de forma particularizada, reforçando a desigualdade jurídica e implicando a sua atualização e o reforço dos já conhecidos traços da cultura jurídica brasileira?

Os dados coletados em nossas pesquisas, referenciadas ao longo deste texto, sugerem existir categorias implícitas ao sistema jurídico brasileiro, que organizam o pensamento e impõem estruturas mentais que informam os processos decisórios dos juízes. Isso possibilita que os mesmos façam sentido para aqueles socializados neste sistema, isto é, o do campo do Direito. Ao cabo, essas categorias permitem a atuação desigual do próprio Poder Judiciário, com a manutenção da (des)igualdade jurídica - que segue naturalizada.

Ao conjunto dessas categorias denominamos gramática decisória ${ }^{3}$. A gramática é o conjunto de regras individuais acionadas para determinado uso de uma língua, aqui, especificamente, para o uso da linguagem decisória dos juízes. Ela é o sistema recorrente ao falar, para que os discursos façam sentido para aqueles socializados neste mesmo sistema de significados.

E o contexto da pandemia da covid-19 no Brasil é um fato superveniente que nos ajuda a explicitar como essas formas judiciais de decidir reproduzem a desigualdade, e como a lógica do contraditório orienta a ética corporativa judicial (R. K. Lima, 
2013), demonstrando que associações e instituições judiciárias adquirem características de corporações ${ }^{4}$. Tal fato particulariza a interpretação das regras, aplicando-as como se levasse em consideração o que representa como interesse público, em que a noção de público está vinculada a uma perspectiva estatal que, travestida de um discurso representativo da soma de interesses individuais, na verdade reflete interesses particulares de corporações do Estado ${ }^{5}$.

Nos últimos anos temos nos dedicado a pesquisar as representações e as práticas burocráticas e judiciárias da (re)produção jurídica da desigualdade no Brasil e em perspectiva comparada (Amorim, 2017; Angelo \& Oliveira, 2021; Baptista, 2013; Corrêa, 2012; Duarte \& Iorio Filho, 2015; Ferreira, 2004; Geraldo, 2019; M. L. T. Lima, 2017; R. K. Lima, 2019a; Mendes, 2012; Nuñez, 2020; L. R. C. Oliveira, 2011b) ${ }^{6}$. Esse contraste tem nos mostrado como o direito brasileiro hierarquiza tanto os membros das instituições judiciárias quanto nossa população, em termos de atribuição e de aplicação de direitos. Na sociedade brasileira, apesar dos preceitos constitucionais republicanos, não existe ainda uma estrutura jurídica ordinária que assegure um mínimo de direitos comuns e compartilhados por todos os diferentes cidadãos. O que há é a aplicação de um conjunto de privilégios atribuídos a certos segmentos da sociedade, que são chamados de "direitos".

A diferença em relação às demais sociedades ocidentais é, portanto, que nelas a desigualdade jurídica é vista como um problema (Bisharat, 2018). Tanto assim que, em contraste com o ritual autoritário brasileiro, descrito por DaMatta (1979), em que se enuncia, sem constrangimentos e com aceitação, a frase "Você sabe com quem está falando?"7 para reforçar a hierarquia e a nossa crônica "alergia à igualdade" (DaMatta, 2020, p. 9), nos Estados Unidos, o rito igualitário responderia "Who do you think you are?" e, na Argentina, a reação viria irada, ainda que reforçando, de certo modo, a hierarquia, e contestaria: "¿Y a mí que mierda me Importa?" (O'Donnell, 1984). Em tais sociedades, a inexorável desigualdade econômica produzida pelo mercado é que gera as desigualdades sociais, e a atuação do sistema jurídico pode servir para mitigá-las, compensando-as com um tratamento igualitário, na elaboração da lei e na sua aplicação. Já no caso brasileiro, a desigualdade está inscrita no próprio sistema jurídico, no seu imaginário ${ }^{8} \mathrm{e}$ na sua operacionalização, como parte integrante e indispensável dele, sistematizando juridicamente as desigualdades sociais, políticas e econômicas. Tal naturalização da desigualdade jurídica, anterior à desigualdade econômica, é uma barreira ao funcionamento regular e regulado do mercado, além de ser uma expressão de representações culturais de uma sociedade hierarquizada. Constitui-se também em referência e suporte para a sua reprodução, em que pode florescer um individualismo perverso, que nunca se identifica com o "outro", mesmo que este seja seu semelhante, no qual, de forma ambígua, a lei é vista, ora como uma "punição" para alguns, ora como fonte para assegurar tratamentos benéficos para outros, mas não como um instrumento que deve efetivamente assegurar os mesmos direitos e deveres para todos, mantendo assim relações de complementaridade e não de competição social ( $R$. K. Lima, 2019b).

O atual contexto da pandemia da covid-19 evidencia a reiterada naturalização das desigualdades estruturais de nossa sociedade em seus variados níveis. Portanto, não é incomum vermos notícias jornalísticas acerca de casos e de decisões judiciais - seja de juízes de primeira instância, seja dos tribunais - que recorrentemente são seletivas tanto na concessão de privilégios, confundidos com direitos diferenciados e especiais, quanto na distribuição desigual de deveres e penalidades; e que são aparentemente tidas como extraordinárias ou como exceções por essas próprias instituições (Amorim, Baptista, Duarte, M. L. T. Lima \& R. K. Lima, 2021).

Partindo desse debate e da descrição de alguns casos, analisamos e demonstramos que, apesar de toda a excepcionalidade atual das novas medidas sanitárias, restritivas de circulação de pessoas e de funcionamento das instituições privadas e públicas, inclusive as judiciárias - foco das nossas reflexões -, estas atingem desigualmente diferentes pessoas. Desta forma, selecionamos alguns eventos que consideramos paradigmáticos na explicitação da justiça brasileira sob medida ${ }^{9}$, ou seja, na medida da sua desigualdade. Isso viabiliza distribuições da justiça a quem merece e em diferentes níveis, dependendo das partes envolvidas, dando assim a cada um o que the cabe, como medida de justiça. Nesse cenário, a imprevisibilidade e a insegurança são o preço que pagamos pela manutenção hígida dessa desigualdade jurídica estrutural.

\section{A ausência de direitos civis no Brasil: Entre direitos e privilégios}

Na ausência de direitos civis - aqui considerados não como um rol abstrato enumerado em textos normativos (pois este rol normativo no Brasil há), mas como um mínimo comum de direitos, distribuídos igualmente para todos os diferentes cidadãos -, o Poder Judiciário brasileiro especializou-se na distribuição desigual de direitos, tornando-os privilégios e seguindo o brocardo jurídico de que "a regra da igualdade é aquinhoar desigualmente os desiguais na medida em que se desigualam", como já desenvolvido por Rui Barbosa em sua "Oração aos Moços"10, e assimilado pela doutrina e pela prática jurídica. 
O seguimento regular do processo judicial e das suas formas processuais não é visto pelos operadores desse campo como garantidor de direitos; e tampouco assegura uma previsibilidade do resultado do processo, porque a desigualdade de decisões corresponde à necessária distribuição desigual de direitos em uma sociedade de desiguais juridicamente. Não há, assim, um mínimo de direitos a que todos os diferentes cidadãos sejam igualmente merecedores, mas gradações de direitos segundo seu merecimento, que nos remete ao mundo da pessoa (e não do indivíduo ${ }^{11}$ ) de Roberto DaMatta (1979) - que se caracteriza pela dimensão da particularidade, da pessoalidade e de distintas posições e hierarquias. E é em razão desse merecimento aquilatado pelo juiz, pela lente da particularização, que os direitos são distribuídos, cabendo a cada um o que lhe é devido, por ser pessoalmente merecido. Como referência, segundo L. R. C. Oliveira (2011b, p. 42), no Brasil, confere-se tratamento desigual e privilegiado às pessoas conforme a sua "substância moral".

L. R. C. Oliveira $(2010,2011 a)$ associa a concepção de igualdade como tratamento uniforme à igualdade de direitos e a concepção de igualdade como tratamento diferenciado à justificação de privilégios - e destaca que a singularidade brasileira está na arbitrariedade da definição entre os campos de vigência dessas duas concepções de igualdade ou mesmo da indistinção entre o exercício de direitos e de privilégios, constituindo a existência de uma sensibilidade cívica brasileira muito própria.

Diferentemente da cultura jurídica dos países anglo-saxões, que se apresenta a partir de uma perspectiva igualitária e individualista, no Brasil, a posição do direito como mecanismo compensatório da desigualdade social se mostra, em vez de acolhedora e extensiva, como restritiva dos direitos da cidadania brasileira. Marshall (1967, p. 107), quando demonstra que a concepção de cidadania é constituída de direitos civis, políticos e sociais, o faz para explicitar justamente que tais direitos surgiram - nos séculos XVIII, XIX e XX - com o propósito de dar conta da desigualdade (incontrolável) fabricada e produzida pelo mercado capitalista.

Justamente, considerando a desigualdade social inevitável em sociedades de mercado, caberia ao Estado, no âmbito dos direitos de cidadania, promover a igualdade jurídica desses cidadãos socialmente - e inevitavelmente - desiguais. Nos termos de R. K. Lima (2004, p. 50):

(...) então, afigura-se claramente a ideia de que esse tipo de direito [constituído pelo elemento civil dos direitos da cidadania] e os tribunais são instituídos para a proteção dos indivíduos - antes súditos, depois cidadãos da República. Há diferenças, entretanto, do ponto de vista dos fundamentos da desigualdade, nos dois contextos. Pois, para Marshall, se no Antigo Regime a desigualdade está fundamentada moral e juridicamente no status, afirmando-se jurídica e politicamente o modelo da pirâmide de que falaremos mais tarde, a sociedade republicana, em que se garantiu a igualdade jurídica aos cidadãos, vai justificar a desigualdade pelas diferenças de performance entre os cidadãos no mercado. Assim, é a igualdade jurídica diante da lei e dos tribunais que vai fornecer a justificativa moral da desigualdade econômica, política e social na sociedade, cujo modelo jurídico-político pode ser representado por um paralelepípedo: a ideia de igualdade diante da lei e dos tribunais permite a desigualdade de classes nas esferas econômica, política e social, inerente ao mercado (...).

Esta percepção igualitária dos direitos de cidadania, expressa por Marshall (1967), impediria, portanto, ao contrário do que se verifica no direito brasileiro, o reconhecimento (e a reverberação) da desigualdade existente no mercado como objeto de compensação no âmbito do sistema de justiça, deixando, para a esfera das políticas públicas governamentais, o espaço de atuação das compensações das desigualdades no acesso aos direitos, de forma particularizada.

Ou seja, em resumo, o que interessa pontuar é que, no caso brasileiro, esse movimento não se realizou no campo jurídico de maneira análoga à de outras repúblicas europeias e americanas. Desse modo, o papel compensatório e tutelar do direito, no lugar de fortalecer os direitos da cidadania, tal como aponta Marshall (1967), os amputa, na medida em que trata os cidadãos como eternos menores inimputáveis e incapazes de serem vistos como sujeitos de direitos, carentes de tutela estatal (Carvalho, 2005; Faoro, 2008).

Nesse contexto, o sistema de desigualdades jurídicas explícitas, vigente em nossa sociedade - ilustrado, de um lado, por exemplo, pela prisão especial ${ }^{12}$ e pelo foro privilegiado ${ }^{13}$ e, de outro, pela proteção dos fracos e hipossuficientes nos processos judiciais -, já internalizado e incorporado por nossas instituições, faz com que a nossa tradição jurídica, em vez de desconstruir privilégios em busca de tratamentos uniformes aos sujeitos naturalmente diferentes, estenda esses tratamentos particularizados ao máximo de segmentos sociais possível, criando, com isso, em plena república federativa, uma ambiguidade incompreensível, que, por sua vez, gera sucessivos e intermináveis mecanismos de desigualdades entre seus cidadãos. É como se funcionássemos, seletivamente, ora como aristocráticos, ora como republicanos. $\mathrm{E}$, na pandemia da covid-19, isso ficou evidenciado de forma bastante pedagógica, para que não restasse nenhuma dúvida 
sobre a confusão jurídica entre direitos e privilégios que persistimos em manter (L. R. C. Oliveira, 2018).

$\mathrm{Na}$ dimensão em que pensamos a questão da desigualdade jurídica no Brasil, a partir da pandemia da covid-19, pretendemos explicitar a desigualdade de tratamento a que fazemos referência, através da descrição de alguns casos administrados pelo Judiciário brasileiro.

Em geral, são situações que selecionamos para nos permitir antever duas relações com a desigualdade jurídica. De um lado, estão as que revelam a compreensão corporativa que o Judiciário tem de si próprio, na defesa de demanda por direitos particularizados, que lhes asseguram uma proteção especial, derivada da autoridade emanada deste Poder e que se explicita na situação de risco sanitário causado pela pandemia da covid-19. E, de outro, trazemos as próprias decisões judiciais, nas quais o tratamento desigual tem sido um vetor na apreciação dos pedidos de liberdade de réus presos em razão da pandemia da covid-19, que ora são concedidos, ora não.

Assim, essas situações estão categorizadas em três tipos de casos que envolvem o Judiciário no atual contexto: casos de auxílio-saúde, casos de "fura-fila" da vacinação contra a covid-19 e casos de tratamento desigual na apreciação de pedidos de liberdade de réus presos.

A primeira categoria de casos decorre da Resolução n. ${ }^{0} 04$ de $2021^{14}$, em que o Tribunal de Justiça, o Ministério Público e a Defensoria Estadual do Estado do Rio Grande do Sul instituíram um auxílio financeiro de saúde suplementar para custear despesas com planos médicos de servidores, incluindo os aposentados. O valor máximo para esse auxílio será de $10 \%$ dos salários, que, no caso dos magistrados, chega a $\mathrm{R} \$ 3.500,00$, por exemplo ${ }^{15}$. De forma semelhante, o Tribunal de Justiça do Estado do Ceará implementou a Política de Atenção Integral à Saúde de Magistrados e Servidores do Poder Judiciário. Benefícios análogos também ocorreram em outros estados brasileiros, incluindo o "bônus-covid" de até $\mathrm{R} \$ 1.000$ para promotores e procuradores do Mato Grosso, licença-prêmio a juízes do Pará, aumento salarial de servidores públicos e home office até janeiro para funcionários do Supremo Tribunal Federal ${ }^{16}$.

Paradoxalmente, embora a Constituição da República Brasileira de 1988 institua a saúde como um direito social, portanto, para todos os cidadãos, nenhuma política pública estadual ou nacional semelhante à "Atenção Integral à Saúde", específica para o momento da pandemia da covid19, foi instituída para custear despesas de saúde para os demais trabalhadores que são de fora do Judiciário e de instituições correlatas ${ }^{17}$. O que tais práticas reforçam é que alguns têm mais direitos civis que outros, inclusive na conjuntura sanitária excepcional atual ${ }^{18}$.
A segunda categoria de casos, que intitulamos de "fura-fila" da vacinação contra a covid-19, é igualmente exemplar para discutir o que DaMatta e Junqueira (2017) chamam de "mentalidade do preferencial". O "fura-fila" é o cidadão que não respeita a ordem de uma fila de espera e passa à frente dos demais, se apropriando de um lugar privilegiado, e excepcionando a regra da isonomia.

A fila, segundo DaMatta e Junqueira (2017), materializa diversos elementos de como o brasileiro, numa sociedade desigual, vive o sistema democrático, e, em sentido contrário, a aversão às filas e a prática de "furá-las" decorre de nossa cultura avessa à igualdade, que se espraia para além das relações sociais, se reproduz e ganha escala também nas instituições do Estado.

Na pandemia da covid-19 não foram raros os casos de "fura-fila" para vacinação. Porém, aqui, destacamos os pedidos feitos pelo Supremo Tribunal Federal (STF) e pelo Superior Tribunal de Justiça (STJ), através de ofícios institucionais encaminhados aos institutos Fiocruz e Butantan ${ }^{19}$, buscando prioridade para assegurar a vacinação de ministros e servidores ${ }^{20}$. Após a publicização dos pedidos na mídia e a negativa formal da reserva de doses, o Presidente do STJ se manifestou no sentido de que a intenção de compra de vacinas vem sendo manifestada por diversos órgãos públicos que realizam campanhas de imunização entre seus funcionários; e que se trataria, portanto, de um "protocolo comercial", visando adiantar um pedido para quando houver disponibilidade. Já no âmbito do STF, a polêmica gerou a exoneração do médico que exercia a função de Secretário de Serviços Integrados de Saúde da Suprema Corte. Segundo o Ministro Presidente do STF, o pedido foi feito sem o seu conhecimento. Já o médico esclareceu que "nunca realizou ato sem a ciência dos seus superiores"21. Para além desses ofícios, outros pedidos de prioridade de vacinação foram feitos ou debatidos no âmbito do TST (Tribunal Superior do Trabalho), da Ordem dos Advogados do Brasil e do Ministério Público 22 .

A terceira categoria de casos que ora discutimos articula tratamento desigual na apreciação de pedidos de liberdade de réus presos em razão da pandemia da covid-1923.

Esta pandemia, especialmente em razão de seus altos índices de contágio, potencializou o risco sanitário para aquelas pessoas em estado de privação de liberdade, já que os presídios no Brasil, assim como em muitas outras partes, não têm condições de assegurar as medidas recomendadas e necessárias para evitar a transmissão e contaminação pelo vírus. Tanto é que o Conselho Nacional de Justiça (CNJ), órgão incumbido pela Constituição brasileira de zelar e promover o controle e a transparência administrativa e processual, no Poder Judiciário brasileiro, com base nas posições públicas assu- 
midas pela Organização Mundial da Saúde (OMS), expediu, em março de 2020, a Recomendação n.0 $62^{24}$, destinada aos juízes e tribunais no sentido da "adoção de medidas preventivas à propagação da infecção pelo novo Coronavírus (Covid-19) no âmbito dos sistemas de justiça penal e socioeducativo", inclusive no sentido de reavaliar as prisões provisórias nesse contexto.

A partir desta recomendação, numerosos pedidos de liberdade provisória ou de comutação de regime de cumprimento de pena foram formulados perante os juízos competentes, no intuito de assegurar ao preso interessado sua saúde e liberdade, que por algumas vezes foram concedidos e por muitas outras, não, sem que da leitura das peças processuais se possa ao certo identificar os elementos objetivos que levaram à decisão de soltura e que deveriam ser aplicados em situações análogas se a igualdade de tratamento para casos semelhantes fosse um vetor interpretativo por si só.

Um caso bastante rumoroso e que recebeu muita atenção da mídia 25 foi o de "Fabrício Queiroz e sua mulher"26, no qual o STJ, por decisão da Presidência, em 2020, deferiu a prisão domiciliar para ambos, com base em razões humanitárias. Ele, por se encontrar doente, em tratamento contra um câncer, e ela, a despeito de estar foragida, para que pudesse cuidar de seu marido, mostrando-se o tribunal sensibilizado com as condições dos presídios brasileiros.

É de sabença geral que a crise mundial de Covid-19 trouxe triste e diferenciada realidade a ser enfrentada por todos, inclusive pelas autoridades judiciárias. Nesses tempos extraordinários, é preciso atenção redobrada com a saúde em nosso país e dessa preocupação não se podem afastar os riscos naturais do sistema penitenciário nacional presídios cheios, casas de detenção lotadas, higiene precária. (Decisão do Ministro João Otávio de Noronha, Presidente do STJ, HC N. ${ }^{\circ}$ 594360-RJ, 2020)

Inclusive este caso foi recebido pela advocacia como uma sinalização de que o STJ, daí para adiante, adotaria essa postura tida como humanitária, sendo o mesmo ainda invocado como precedente no tema. Porém, não foi assim que se passou e, segundo levantamento feito pelo portal $\mathrm{G} 1^{27}$, junto ao próprio STJ, dos 725 pedidos similares aos do caso Queiroz, o Presidente do STJ concedeu apenas $18(2,5 \%)$ prisões domiciliares. De acordo com a jornalista Rosanne D'Agostino (2020, p. 8), "Alguns dos 18 pedidos concedidos por Noronha foram de prisão domiciliar a um homem portador de linfoma não Hodgkin abdominal; a duas mães para cuidar dos filhos menores; e a uma advogada idosa e portadora de hipertensão aguda grave".
Um exemplo bastante ilustrativo - e que aponta para a ausência de marcadores objetivos nas decisões - pode ser visto no habeas corpus coletivo $^{28}$ (STJ HC. 596189-DF, 2020), impetrado por membros do Coletivo de Advocacia em Direitos Humanos (CADH), e que pedia a prisão domiciliar em favor de todas as pessoas presas preventivamente pertencentes ao grupo de risco decorrente da pandemia da covid-1929 e que se encontravam no sistema prisional do Distrito Federal. O pedido se fundamentava nas razões humanitárias que levaram à edição da Recomendação 62, citando expressamente, em sua inicial, o caso Queiroz como referência interpretativa. O pedido foi indeferido, sendo adotada, entre outros argumentos, a necessidade de ponderação de direito e a indispensabilidade de uma "análise atenta a respeito da situação peculiar de cada um" dos presos, a despeito de o relator Ministro Sebastião Reis Júnior consignar que não desconhecia "os dados alarmantes relatados na impetração, a justificar a adoção de medidas efetivas e necessárias à preservação da saúde e da vida de todas as pessoas que se encontram sob a custódia do Estado" (Reis, 2020, p. 30).

Outro caso de indeferimento é o de três habeas corpus coletivos (STJ HCs. 575.315, 575.314 \& $576.036,2020)$ impetrados pela Defensoria Pública de São Paulo, requerendo a liberdade ou o regime domiciliar para presos idosos custodiados em cidades paulistas. Ao indeferir o pedido, citando a decisão do Ministro Rogerio Schietti Cruz, no HC 567.408 (2020) acima referenciado, o relator destacou (conforme noticiado pelo próprio STJ) que "o entendimento predominante no STJ é de que a pandemia deve ser sempre levada em conta na análise de pleitos de libertação de presos, mas isso não significa que todos devam ser liberados, pois ainda persiste o direito da coletividade em ver preservada a paz social" (STJ, 2020, p. 6).

Gostaríamos também de chamar atenção para o caso do ex-governador do estado do Rio de Janeiro - Sérgio Cabral -, preso desde 2016, por acusação de crimes de lavagem de dinheiro e corrupção. Seu habeas corpus (STJ HC. 567.408-RJ, 2020), requerendo prisão domiciliar, foi apreciado pelo Superior Tribunal de Justiça e indeferido, entendendo a Corte que prisões imprescindíveis para a garantia da ordem pública e da ordem econômica, da instrução criminal e da aplicação da lei penal (todos esses conceitos de ambiguidade semântica) devem ser mantidas, a despeito da pandemia e recomendação do Conselho Nacional de Justiça (CNJ). Segundo o relator da ação, Ministro Rogerio Schietti Cruz:

A crise do novo coronavírus deve ser sempre levada em conta na análise de pleitos de libertação de presos, mas, iniludivelmente, não é um passe livre para a liberação de todos, 
pois ainda persiste o direito da coletividade em ver preservada a paz social, a qual não se desvincula da ideia de que o sistema de justiça penal há de ser efetivo, de sorte a não desproteger a coletividade contra os ataques mais graves aos bens juridicamente tutelados na norma penal. (Cruz, 2020, p. 2)

Com esses casos relatados, independentemente dos questionamentos que podem ser feitos em razão da figura do réu, o fato é que, a despeito de serem portadoras de doenças que as colocariam como parte do grupo de risco da covid-19, nem todas as pessoas envolvidas receberam o mesmo benefício penal por conta das razões humanitárias apontadas pelo CNJ. Situações análogas com desfechos desiguais.

\section{Considerações finais: O novo é a reafirmação do velho}

Como já registramos em outra oportunidade (Amorim, Baptista, Duarte, M. L. T. Lima \& R. K. Lima, 2021), tradição e modernidade no Brasil não se sucederam ou se sobrepuseram, como aconteceu em outras sociedades ocidentais, mas convivem em uma conformidade ambígua. Possuímos discursos e práticas que fazem, reiteradamente, do novo a reafirmação do velho, no sentido de travestir práticas tradicionais inquisitoriais e hierárquicas no campo do Direito com discursos acusatoriais, igualitários, universais e inclusivos (M. L. T. Lima \& R. K. Lima, 2020). Como se pode ver, dualidades há muito superadas em outras sociedades ocidentais, tais como honra e dignidade, inquirição e inquisitorialidade, desigualdade e diferença, direito e privilégio, ainda persistem no Brasil, inclusive no contexto da pandemia da covid-19, evidenciando que só o exame mais acurado das contradições, dos dilemas e dos paradoxos verificados entre os discursos normativos e as práticas judiciárias permite compreender melhor o campo do Direito brasileiro.

No Brasil, e a pandemia é exemplar nesse sentido, não fomos treinados no exercício da cidadania plena, no sentido de que não fomos socializados a cumprir igualmente as regras, que são sempre particularizadas. Ainda hoje, há uma lógica colonial corporativa, que expressa uma ética em que as instituições judiciárias aplicam as regras de forma particularizada, atrelando à noção de público uma perspectiva estatal que, travestida de um discurso representativo da soma de interesses individuais, na verdade reflete interesses particulares das próprias corporações do Estado.

Nesse sentido, o "abrasileiramento da burocracia" no Brasil se deu de forma peculiar, pois, embora tivessem ocorrido enlaces entre a elite jurídica e a corte, é certo que aqui as instituições judiciárias atualizaram essas relações de forma que mescla- ram seu papel público a seus interesses privados, desnorteando essas noções, entre o público e o privado, e reverberando a preponderância de uma ética particularista que vigora desde as raízes do nosso Brasil até hoje (Schwartz, 2011). E os casos que mencionamos aqui, sobre a busca reiterada e naturalizada por privilégios na pandemia, são a mais forte explicitação dessa ordem corporativa, evidenciando especificidades da sociedade brasileira em relação a outras sociedades ocidentais.

Somando-se a essa cultura social, as marcas de nossa cultura jurídica produzem-se em uma estrutura de poder a serviço da desigualdade jurídica e, consequentemente, do tratamento não uniforme, aplicado aos casos concretos e às vidas dos cidadãos desta república, que cada vez mais se fragiliza, quando um dos seus Poderes se estrutura nessa dimensão.

\section{Notas}

1 Veja, por exemplo, em: Chulov (2020).

2 Veja-se por exemplo o disposto no artigo 5.0 da Constituição Brasileira em vigor (CRFB, 1988), o qual estabelece que "Todos são iguais perante a lei, sem distinção de qualquer natureza, garantindo-se aos brasileiros e aos estrangeiros residentes no País a inviolabilidade do direito à vida, à liberdade, à igualdade, à segurança e à propriedade (...)."

3 Essas categorias integram o que Duarte e Iorio Filho (2012, p. 191) chamam de gramática decisória. "Assim, uma gramática decisória implica na identificação de um sistema de regras lógicas que informam os processos mentais de decisão; fórmulas que regulam o pensamento e estruturam as decisões; isto é, estruturas que orientam a construção do discurso que se materializa nas decisões judiciais. Essa gramática estaria internalizada, pois é ela que, pela repetição e interação entre os atores do campo jurídico, habilita o juiz a compreender o sentido dado ao direito para então decidir. É compartilhada entre seus 'falantes' (os juízes) que a praticam de forma espontânea e a naturalizam pela força da repetição. São essas regras que permitem o reconhecimento espontâneo e o uso das estruturas que regularizam e viabilizam a produção do discurso decisório dos juízes, a partir da adoção de estratégias argumentativas/discursivas que resultará na fundamentação de suas decisões."

4 A própria forma de categorização e organização dos registros em forma de dados informatizados do Conselho Nacional de Justiça (CNJ), para fins de construção de seus relatórios anuais intitulados "Relatório Justiça em Números", explicita essa lógica corporativa de gestão dos processos judiciais. Seus índices, tais como taxas de congestionamento processual, indicadores de produtividade dos magistrados e indicadores de produtividade dos servidores da área judiciária, possuem poucos detalhes de diagnóstico, avaliando apenas o movimento quantitativo de processos judiciais, o número de funcionários e o orçamento dos fóruns e tribunais em cada estado, por ano, sem considerar os tipos de demanda, as formas de administração dos conflitos, o perfil das partes conflitantes e demais possibilidades de registro de microdados. 
As metas corporativas quantitativas sobressaem sobre todos os outros aspectos. Nesse sentido, Cicourel (1998) dispõe que os registros quantitativos das instituições judiciais podem revelar mais sobre suas práticas do que sobre os fatos que se pretendia quantificar. Veja mais detalhes em: Conselho Nacional de Justiça (2018). Dados Estatísticos. Brasília: Autor. Retirado de https://www. cnj.jus.br/programas-e-acoes/priorizacao-do-1o-grau/ dados-estatisticos-priorizacao/.

5 O Judiciário é apresentado como corporativo, pois, ainda hoje, o Brasil mantém uma lógica colonial corporativa, que expressa uma ética em que as instituições judiciárias aplicam as regras de forma particularizada, atrelando à noção de público uma perspectiva estatal que, travestida de um discurso representativo da soma de interesses individuais, na verdade reflete interesses particulares das próprias corporações do Estado. O "abrasileiramento da burocracia" no Brasil se deu de forma peculiar, pois, embora tivessem ocorrido enlaces entre a elite jurídica e a corte, é certo que aqui, as instituições judiciárias atualizaram essas relações de uma forma que mesclaram seu papel público a seus interesses privados, desnorteando essas noções, entre o público e o privado, e reverberando a preponderância de uma ética particularista que vigora desde as raízes do Brasil até hoje. E os casos que mencionamos aqui, sobre a busca reiterada e naturalizada por privilégios na pandemia, são a mais forte explicitação dessa ordem corporativa. Segundo Schwartz (2011): "O sistema de tribunais reais e eclesiásticos era, ao que tudo indica, um mecanismo altamente racionalizado de administração judicial, um sistema baseado no conceito de que a obrigação de fornecer os meios legais para corrigir erros constituía a essência da autoridade do rei. Mas o observador se impressiona, especialmente, ante a organização judicial real, com as múltiplas responsabilidades dos magistrados e sua tendência a assumir funções extrajudiciais. No processo de centralização, a Coroa portuguesa encontrara, no sistema judiciário, uma ferramenta conveniente e eficaz para a ampliação do poder real, e, no corpo de magistrados profissionais do sistema, a Coroa não apenas encontrou, mas forjou um aliado competente." Além disso, a atual Constituição da República Federativa do Brasil - em seu artigo 92, incisos I a VII - dispõe que não só os Tribunais, mas também os Juízes do Trabalho, Juízes Eleitorais, Juízes Militares e Juízes dos Estados e do Distrito Federal são órgãos do Poder Judiciário, reforçando a ideia de que, enquanto órgãos, os magistrados compõem o corpo do Judiciário como um poder e não como um serviço.

6 Boa parte desses trabalhos empíricos demonstra como tais práticas se reproduzem de maneira informal e quase invisível, mas compartilhando valores corporativos que orientam práticas institucionais locais.

7 No caso específico da vacinação contra a covid-19 no Brasil e sua relação com a república à brasileira, explicita DaMatta (2021) em "Uma vacina contra privilégios": "Iniciamos a vacinação dentro de um campo politizado precisamente pela velha enfermidade de um 'você sabe com quem está falando?' - o famoso 'quem é que manda?!' - que prolonga a doença e a morte. E assim será até nos convencermos de que a cura dos privilégios chega com a vacina da democracia - essa forma de organização coletiva simples e frágil que, como os bons remédios, requer uma enorme paciência, um exigente bom-caratismo e um persistente bom senso." Retirado de https://outline.com/SK7cFc.
8 Especificamente sobre o tratamento legal desigual, ver Bruno Rezende Silva (2017), e sobre a questão do imaginário jurídico, conferir Maria Carolina Freitas (2020).

9 No discurso jurídico brasileiro, e até no senso comum, Judiciário e Justiça são tidos, inclusive, como sinônimos, o que se explicita em certas expressões nativas, como, por exemplo: "ir à Justiça", "ser da Justiça", "trabalhar na Justiça" e "receber Justiça". O Judiciário, ao mesmo tempo que é um poder, também é tido como produtor de justiça(s).

10 "A parte da natureza varia ao infinito. Não há, no universo, duas coisas iguais. Muitas se parecem umas às outras. Mas todas entre si diversificam. Os ramos de uma só árvore, as folhas da mesma planta, os traços da polpa de um dedo humano, as gotas do mesmo fluido, os argueiros do mesmo pó, as raias do espectro de um só raio solar ou estelar. Tudo assim, desde os astros no céu, até os micróbios no sangue, desde as nebulosas no espaço, até aos aljôfares do rocio na relva dos prados. A regra da igualdade não consiste senão em aquinhoar desigualmente aos desiguais, na medida em que se desigualam [grifo nosso]. Nesta desigualdade social, proporcionada à desigualdade natural, é que se acha a verdadeira lei da igualdade. O mais são desvarios da inveja, do orgulho, ou da loucura. Tratar com desigualdade a iguais, ou a desiguais com igualdade, seria desigualdade flagrante, e não igualdade real. Os apetites humanos conceberam inverter a norma universal da criação, pretendendo, não dar a cada um, na razão do que vale, mas atribuir o mesmo a todos, como se todos se equivalessem" (Barbosa, 1999, p. 26).

11 Lembramos que, para DaMatta, Lanna e Moraes (1998), o indivíduo é o sujeito por excelência das leis universais e, assim igualitárias, que trazem a modernização ocidental para a sociedade e que tem na rua seu espaço de agência, marcado pela impessoalidade. Em entrevista, DaMatta explica: "O que representa a rua? É o mundo do Estado, o mundo da política, o mundo da consciência ocidental burguesa, constitucional, que aparece na Revolução Francesa, na Revolução Britânica, no republicanismo americano" (DaMatta, Lanna \& Moraes, 1998, p. 201). Já a pessoa, que impera no mundo da casa (espaço privilegiado da intimidade e da proteção), é o sujeito das relações sociais regidas pela pessoalidade, particularizações, subjetividades e moralidades, nas quais cada um é distinto do outro e ninguém é igual a ninguém, submetendo a pessoa a distintas dimensões hierarquizadas, que se organizam por diversos fatores como afeto, honra, vulnerabilidade, etc.

12 A prisão especial está prevista no artigo 295 do Código de Processo Penal brasileiro. Trata-se de um privilégio processual que garante o tratamento desigual para cidadãos brasileiros, em função de cargo, função, emprego, atividade ou grau de formação, autorizando-os que fiquem reclusos em cela especial, diferenciada do sistema carcerário comum, até o trânsito em julgado da sentença penal condenatória.

${ }^{13} \mathrm{O}$ foro privilegiado - ou foro por prerrogativa de função - está previsto nos artigos 53 e 102 da Constituição da República e é um mecanismo que retira dos juízes singulares de primeira instância a competência penal em ações que envolvem autoridades públicas, em razão do cargo ou função.

${ }^{14}$ Lei n. 11.419, de 19 de dezembro de 2006. 
15 Tribunal de Justiça, Ministério Público e Defensoria Pública do RS criam auxílio-saúde para servidores e magistrados (2021, março 10)

16 Moura \& Valfré, 2020).

17 Há o "Auxílio Emergencial 2021", que é um benefício financeiro concedido pelo Governo Federal para pessoas que atendam aos requisitos: não possuam emprego formal ativo; não recebam outros auxílios federais; e tenham renda familiar mensal por pessoa abaixo de meio salário mínimo (o que equivale atualmente a $\mathrm{R} \$ 550,00$ ). Se a família for composta por apenas uma pessoa, o benefício é de R\$150,00 por mês; por mais de uma pessoa, o benefício é de $\mathrm{R} \$ 250,00$ por mês; se for chefiada por mulher sem cônjuge ou companheiro, com pelo menos uma pessoa menor de dezoito anos de idade, receberá, mensalmente, $\mathrm{R} \$ 375,00$. O número máximo de auxílios emergenciais mensais que uma pessoa pode receber são quatro. Apesar disso, não há um auxílio governamental específico para custas médicas decorrentes da covid-19. Retirado de https://www.caixa.gov.br/auxilio/auxilio2021/ Paginas/default.aspx.

18 Ver mais sobre Sujeição sanitária e cidadania vertical no Brasil em K. R. Lima e M. S. Campos (2021)

19 Íntegra dos ofícios do STF e da Fiocruz. Retirado de https://www.migalhas.com.br/arquivos/2020/12/ fb941666a85001_oficio-stf.pdf e https://www.otempo. com.br/polopoly_fs/1.2428067.1608730181!/menu/ standard/file/Oficio_Fiocruz.pdf.

20 STF e STJ buscaram obter vacinas da covid-19 para ministros e servidores (2020, dezembro 23).

21 Rezende, 2020.

22 Rodrigues, 2020. Segalla, 2020. OAB realizará estudos para viabilizar compra de vacinas para advogados (2021, abril 13).

${ }^{23}$ As decisões referentes aos casos citados podem ser consultadas no site do STJ (https://scon.stj.jus.br/SCON/).

${ }^{24}$ A recomendação pode ser consultada no site do $\mathrm{CNJ}$ (https://atos.cnj.jus.br/atos/detalhar/3246).

25 Bergamo, 2020.

26 Sujeito de investigação por suspeição de colaborar com a família do Presidente Bolsonaro em atividades ilícitas.

27 D'Agostino (2020).

28 O habeas corpus coletivo é um instrumento processual de criação doutrinária e jurisprudencial que objetiva proteger grupo de pessoas em situações similares de violação aos seus direitos de ir e vir, em outras palavras, permitindo-se discutir as arbitrariedades das prisões.

29 Esse grupo de risco, em razão das condições de saúde, foi definido pela Portaria Interministerial (Ministro da Justiça e da Segurança Pública e Ministro da Saúde) n. 07, de 18 de março de 2020.

\section{Referências bibliográficas}

Amorim, M. S. (2017). Conflitos no mercado de bens e serviços: Consumidores e consumidos. Em M. S. Amorim \& R. K. Lima (orgs.), Administração de conflitos e cidadania: Problemas e perspectivas (pp. 268-280). Rio de Janeiro: Autografia.
Amorim, M. S., Baptista, B., Duarte, F., Lima, M. L., \& Lima, R. K. (orgs.) (2021). Dossiê: Pesquisa em direito na perspectiva empírica: Práticas, saberes e moralidades. Antropolítica: Revista Contemporânea de Antropologia, 51(1), 11-36.

Angelo, J., \& Oliveira, L. R. C. (2021). Entre documentos, inquirições e inspeções: A trama da produção de provas em processos de aposentadoria rural nos Juizados Especiais Federais. Em M. S. Amorim, B. Baptista, F. Duarte, M. L. T. Lima \& R. K. Lima (orgs.), Dossiê: Pesquisa em direito na perspectiva empírica: Práticas, saberes e moralidades. Antropolítica: Revista Contemporânea de Antropologia, 51(1), 162-187.

Baptista, B. (2013). Paradoxos e ambiguidades da imparcialidade judicial: Entre "quereres" e "poderes". Porto Alegre: Sergio Antonio Fabris.

Barbosa, R. (1999). Oração aos moços (5.a ed.). Rio de Janeiro: Fundação Casa de Rui Barbosa.

Bergamo, M. (2020, julho 09). STJ dá prisão domiciliar a Queiroz, mas nega a jovem que furtou xampu. Folha de S. Paulo. Retirado de https://www1.folha. uol.com.br/colunas/monicabergamo/2020/07/ stj-da-prisao-domiciliar-a-queiroz-mas-nega-a-jovem-que-furtou-xampu.shtml.

Bisharat, G. (2018). A persistência das desigualdades raciais no sistema de justiça criminal dos EUA. Revista Juris Poiesis, 21(27), 256-282. Retirado de http://periodicos.estacio.br/index.php/jurispoiesis/ article/viewFile/6168/47965321.

Carvalho, J. (2005). Cidadania no Brasil: O longo caminho (7. a ed.). Rio de Janeiro: Civilização Brasileira.

Cicourel, A. V. (1998). The social organization of juvenile justice. Nova Iorque: John Wiley \& Sons.

Chulov, M. (2020, fevereiro 25). Feverish Iraj Harirchi says disease 'doesn't distinguish between statesman and ordinary citizen'. The Guardian. Retirado de https://www.theguardian.com/world/2020/ feb/25/irans-deputy-health-minister-i-have-coronavirus.

Conselho Nacional de Justiça. (2018). Dados estatísticos. Brasília: Autor. Retirado de https://www.cnj.jus. br/programas-e-acoes/priorizacao-do-1o-grau/ dados-estatisticos-priorizacao/.

Constituição da República Federativa do Brasil de 1988. Brasília. Retirado de http://www.planalto.gov.br/ ccivil_03/Constituicao/Constituicao.html/.

Corrêa, C. (2012). Controvérsias entre o 'Direito de Moradia' em favelas e o Direito de Propriedade Imobiliária na cidade do Rio de Janeiro: 'O Direito de Laje' em questão. Rio de Janeiro: Topbooks.

D'Agostino, R. (2020, julho 26). Ministro do STJ que liberou prisão domiciliar para Queiroz rejeitou outros 700 pedidos sobre Covid-19. G1. Retirado de https://g1.globo.com/politica/noticia/2020/07/26/ ministro-do-stj-que-liberou-prisao-domiciliar-para-queiroz-rejeitou-outros-700-pedidos-sobre-covid-19.ghtml.

DaMatta, R. (1979). Carnavais, malandros e heróis. Rio de Janeiro: Zahar. 
DaMatta, R. (2020). Você sabe com quem está falando? Estudos sobre o autoritarismo brasileiro. Rio de Janeiro: Rocco.

DaMatta, R. (2021, janeiro 20). Uma vacina contra privilégios. O Globo. Opinião. Retirado de https:// oglobo.globo.com/opiniao/uma-vacina-contra-privilegios-24845919.

DaMatta, R., \& Junqueira, A. (2017). Fila e democracia. Rio de Janeiro: Rocco.

DaMatta, R., Lanna, M., \& Moraes, P. (1998). Uma antropologia da sociedade brasileira - Entrevista com Roberto DaMatta. Revista de Sociologia e Política, 10(11), 195-211. Retirado de https:// revistas.ufpr.br/rsp/article/view/39284.

Duarte, F. (2006). Supremo Tribunal Federal e sociedade brasileira: Legitimando a desigualdade jurídica ou a diferença?. Comunicação apresentada no GT 43: Processos Institucionais de Administração de Conflitos no Espaço Público, Goiânia, 1-10. Retirado de https://www.academia. edu/14301626/Supremo_Tribunal_Federal_e_ Sociedade_Brasileira_legitimando_a_desigualdade_jur\%C3\%ADdica_ou_a_diferença.

Duarte, F., \& Iorio Filho, R. M. (2011). A impossibilidade da igualdade jurídica no Brasil. Revista Juris Poiesis, 14(14), 48-62.

Duarte, F., \& Iorio Filho, R. M. (2012). Uma gramática das decisões judiciais: Mesmos casos, decisões desiguais. Revista da Seção Judiciária do Rio de Janeiro, 19(33), 185-204. Retirado de https:// www.jfrj.jus.br/sites/default/files/revista-sjrj/ arquivo/303-1075-2-pb.pdf.

Duarte, F., \& Iorio Filho, R. M. (2015). A lógica do contraditório: Ainda somos medievais. Em G. S. Siqueira, A. C. Wolkmer \& Z. L. Pierdoná (orgs.), História do direito (pp. 1-23). Florianópolis: CONPEDI.

Duarte, F., Iorio Filho, R. M., \& Baptista, B. (2021, março.01). O Sistema Judicial brasileiro em ação e a impossibilidade da igualdade jurídica no Brasil. Blog Ciência e Matemática. O Globo. Retirado de https:// blogs.oglobo.globo.com/ciencia-matematica/post/o-sistema-judicial-brasileiro-em-acao-e-impossibilidade-da-igualdade-juridica-no-brasil.html.

Faoro, R. (2008). Donos do poder: Formação do patronato político brasileiro. Rio de Janeiro: Editora Globo.

Ferreira, M. (2004). O devido processo legal: Um estudo comparado. Rio de Janeiro: Lumen Juris.

Freitas, M. C. R. (2020). A alegoria da igualdade jurídica: Revelando uma sensibilidade jurídica oculta pela dogmática (Tese de doutoramento). Universidade Estácio de Sá, Programa de Pós-Graduação em Direito, Rio de Janeiro.

Fundação Instituto Oswaldo Cruz (Fiocruz). (2020). Desigualdade social e econômica em tempos de Covid-19. Rio de Janeiro: Autor. Retirado de https://agora.fiocruz.br/2020/05/14/desigualdade-social-e-economica-em-tempos-de-covid-19/.

Geraldo, P. H. B. (2019). Políticas públicas judiciárias: Uma abordagem comparativa entre a organização social da justiça no Brasil e na França. Revista Juris Poiesis, 22(28), 309-328.

Lei n. ${ }^{\circ} 11.419$, de 19 de dezembro de 2006. Dispõe sobre a informatização do processo judicial; altera a Lei n. ${ }^{0}$ 5.869, de 11 de janeiro de 1973 - Código de Processo Civil; e dá outras providências. Retirado de https://www.tjrs.jus.br/servicos/diario_justica/dj_principal.php?tp=0\&ed $=6935 \&$ pag $=1$.

Lima, M. L. T. (2017). Próximo da justiça, distante do direito: Administração de conflitos e demandas de direitos no juizado especial criminal. Rio de Janeiro: Autografia.

Lima, R. K. (2004). Direitos civis e direitos humanos: Uma tradição judiciária pré-republicana?. São Paulo em Perspectiva, 18(1), 49-59. Retirado de https://www.scielo.br/pdf/spp/v18n1/22226.pdf.

Lima, R. K. (2013). Entre as leis e as normas: Éticas corporativas e práticas profissionais na segurança pública e na Justiça Criminal. Dilemas: Revista de Estudos de Conflito e Controle Social, 6(4), 549580. Retirado de https://revistas.ufrj.br/index. php/dilemas/article/view/7436.

Lima, R. K. (2019a). A polícia da cidade do Rio de Janeiro: Seus dilemas e paradoxos (3. a ed.) Rio de Janeiro: Amazon.

Lima, R. K. (2019b, janeiro 21). Igualdade jurídica e respeito às diferenças no Brasil: Entre a pirâmide e o paralelepípedo. Blog Ciência e Matemática, $O$ Globo. Retirado de https://blogs.oglobo.globo. com/ciencia-matematica/post/igualdade-juridica-e-respeito-diferencas-no-brasil-entre-piramide-e-o-paralelepipedo.html.

Lima, R. K., \& Campos, M. S. (2021). Sujeição sanitária e cidadania vertical: Analogias entre as políticas públicas de extermínio na segurança pública e na saúde pública no Brasil de hoje. Revista Dilemas IFCS-UFRJ, 14, 1-9. Retirado de https://www. reflexpandemia.org/texto-98?fbclid=IwAR2jEOjL zufOzCJPGLkGhjAL3v_RIb8CpxH9qU6zx0SG82qlm2rkhPhy1to.

Lima, M. L. T., \& Lima, R. K. (orgs.) (2020). Pesquisa empírica no direito e na segurança pública: Doutrina, teoria e práticas. Em Entre normas e práticas: Os campos do direito e da segurança pública em perspectiva empírica (pp. 9-22). Rio de Janeiro: Autografia.

Marshall, T. H. (1967). Cidadania, classe social e status. Rio de Janeiro: Zahar.

Mendes, R. L. T. (2012). Do princípio do Livre Convencimento Motivado: Legislação, doutrina e interpretação de juízes brasileiros. Rio de Janeiro: Lumen Juris.

Moura, R., \& Valfré, V. (2020). Justiça e MP criam 'penduricalhos' em meio à pandemia. Estadão. Retirado de https://politica.estadao.com.br/ noticias/geral,justica-e-mp-criam-penduricalhos-em-meio-a-pandemia,70003297383.

Nuñez, I. (2020). "Aqui nós somos uma família": Brigas e acordos no tribunal do júri. Rio de Janeiro: Autografia. 
OAB realizará estudos para viabilizar compra de vacinas para advogados. (2021, sbril 13). Migalhas. Retirado de https://www.migalhas.com.br/quentes/343566/oab-realizara-estudos-para-viabilizar-compra-de-vacinas-para-advogados.

O'Donnell, G. (1984). ¿Y a mí, que me importa? Notas sobre sociabilidad y política en Argentina y Brasil (Working Paper, N.o 9). Kellogg Institute. Retirado de https://kellogg.nd.edu/sites/default/files/ old_files/documents/009_0.pdf.

Oliveira, L. R. C. (2010). Concepções de igualdade e (des)igualdades no Brasil (uma proposta de pesquisa). Em R. K. Lima, L. Eilbaum \& L. Pires (orgs.), Conflitos, direitos e moralidades em perspectiva comparada (pp. 19-36). Rio de Janeiro: Garamond.

Oliveira, L. R. C. (2011a). Concepções de igualdade e cidadania. Contemporânea Revista de Sociologia da UFSCar, 1(1), 35-48. Retirado de http://www. contemporanea.ufscar.br/index.php/contemporanea/article/view/19.

Oliveira, L. R. C. (2011b). Direito legal e insulto moral: Dilemas da cidadania no Brasil, Quebec e EUA (2. ${ }^{a}$ ed.). Rio de Janeiro: Garamond.

Oliveira, L. R. C. (2018). Sensibilidade cívica e cidadania no Brasil. Antropolítica: Revista Contemporânea de Antropologia, (44), 34-63. DOI: 10.22409/ antropolitica2018.0i44.a41956.

Rezende, C. (2020, dezembro 29). 'Nunca realizei ato sem a ciência dos meus superiores', diz médico exonerado por Fux. Folha de S. Paulo. Retirado de https://www1.folha.uol.com.br/cotidiano/2020/12/ nunca-realizei-ato-sem-a-ciencia-dos-meus-superiores-diz-medico-exonerado-por-fux.shtml.

Ribeiro, L., \& Oliveira, V. (2020, abril 21). O que os registros de homicídios nos ensinam sobre os dados de mortalidade por Covid-19. Blog DADOS. Revista de Ciências Sociais. Retirado de http:// dados.iesp.uerj.br/registros-homicidios/.
Rodrigues, B. (2020, dezembro 23). Depois de Supremo, Tribunal Superior do Trabalho pede vacina. CNN Brasil. Retirado de https://www.cnnbrasil.com.br/ nacional/2020/12/23/depois-de-supremo-tribunal-superior-do-trabalho-pede-prioridade-para-vacina.

Segalla, V. (2020, dezembro 02). Furando a fila: Promotores de SP pedem para receber primeiro a vacina da COVID. Brasil de Fato. Retirado de https://www.brasildefato.com.br/2020/12/02/ furando-a-fila-promotores-de-sp-pedem-para-receber-primeiro-a-vacina-da-covid.

Schwartz, S. (2011). Burocracia e sociedade no Brasil colonial: O Tribunal Superior da Bahia e seus desembargadores, 1609-1751. São Paulo: Companhia das Letras.

Silva, B. (2017). A naturalização da desigualdade jurídica no Brasil a partir da análise de privilégios legais (Dissertação de mestrado). Universidade Estácio de Sá, Programa de Pós-Graduação em Direito, Rio de Janeiro.

Silva, G. (2021). "Caverão vírus, essa mata mais do que a COVID-19!": Sistema de justiça e seus regimes de desumanização em lugares chamados de Favela. Em Dossiê: Entre normas e práticas: Pesquisa empírica no direito em diálogo com as ciências sociais. Revista Juris Poiesis, 24(34), 726-749.

STF e STJ buscaram obter vacinas da covid-19 para ministros e servidores. (2020, dezembro 23). Retirado de https://www.migalhas.com.br/quentes/338289/stf-e-stj-buscaram-obter-vacinas-da-covid-19-para-ministros-e-servidores.

Tribunal de Justiça, Ministério Público e Defensoria Pública do RS criam auxílio-saúde para servidores e magistrados. (2021, março 10). G1. Retirado de https://g1.globo.com/rs/rio-grande-do-sul/ noticia/2021/03/10/tribunal-de-justica-ministerio-publico-e-defensoria-publica-do-rs-criam-auxilio-saude-para-servidores.ghtml.

Esta obra está licenciada com uma Licença Creative Commons Atribuição - 4.0 (CC BY 4.0).

Recebido a 30/05/2021. Aceite para publicação a 27/10/2021.

Bárbara Gomes Lupetti Baptista. Universidade Federal Fluminense, Faculdade de Direito, Departamento de Ciências Judiciárias DCJ/UFF \& Universidade Veiga de Almeida, Programa de Pós-Graduação Stricto Sensu em Direito \& Universidade Federal Fluminense, Instituto de Estudos Comparados em Administração Institucional de Conflitos INCT-InEAC, Rio de Janeiro, Brasil. ORCID: https://orcid.org/000-0001-8342-4543 E-mail: barbaralupetti@id.uff.br Fernanda Duarte. Universidade Federal Fluminense, Faculdade de Direito, Departamento de Ciências Judiciárias - DCJ/UFF \& Universidade Federal Fluminense, Programa de Pós-Graduação Justiça Administrativa - PPGJA/UFF \& Universidade Estácio de Sá, Programa de Pós-Graduação em Direito \& Universidade Federal Fluminense, Instituto de Estudos Comparados em Administração Institucional de Conflitos - INCT-InEAC, Rio de Janeiro, Brasil. ORCID: https://orcid.org/0000-0003-2156-6946 E-mail: fernanda.duarte@id.uff.br

Michel Lobo Toledo Lima. Fundação de Amparo à Pesquisa do Estado do Rio de Janeiro - FAPERJ \& Universidade Federal Fluminense, Instituto de Estudos Comparados em Administração Institucional de Conflitos - INCT-InEAC, Rio de Janeiro, Brasil. ORCID: https://orcid.org/0000-0001-6259-288X E-mail: michell_lobo@hotmail.com 
Rafael Mario Iorio Filho. Universidade Federal Fluminense, Faculdade de Direito, Departamento de Ciências Judiciárias \& Fundação de Amparo à Pesquisa do Estado do Rio de Janeiro - FAPERJ \& Universidade Veiga de Almeida, Programa de Pós-Graduação em Direito \& Universidade Federal Fluminense, Instituto de Estudos Comparados em Administração Institucional de Conflitos - INCT-InEAC, Rio de Janeiro, Brasil. ORCID: https://orcid.org/00000003-3725-5069 E-mail: rafael_iorio@id.uff.br

Roberto Kant de Lima. Universidade Federal Fluminense, Programa de Pós-Graduação em Antropologia - PPGA/ UFF \& Universidade Federal Fluminense, Programa de Pós-Graduação em Justiça e Segurança - PPGJS/UFF \& Universidade Veiga de Almeida, Programa de Pós-Graduação em Direito \& Universidade Federal Fluminense, Instituto de Estudos Comparados em Administração Institucional de Conflitos - INCT-InEAC \& Conselho Nacional de Desenvolvimento Científico e Tecnológico - CNPq \& Fundação de Amparo à Pesquisa do Estado do Rio de Janeiro - FAPERJ, Rio de Janeiro, Brasil. ORCID: https://orcid.org/0000-0003-1367-9318 E-mail: rkantbr@gmail.com 